\title{
Planning polyphase behavior of autonomous intelligent mobile systems in uncertain environments
}

\author{
V. B. Melekhina, Dr. Sc., Tech., Professor, orcid.org/0000-0002-7614-2860, pashka1602@rambler.ru \\ M. V. Khachumovb,c, PhD, Phys. -Math., Senior Researcher, orcid.org/0000-0001-5117-384X \\ aDagestan State Technical University, Imam Shamil Ave., 70, 367015, Makhachkala, Russian Federation \\ bFederal Research Center "Computer Science and Control" of RAS, 60-Letiya Oktyabrya Pr., 9, 117313, \\ Moscow, Russian Federation \\ cProgram Systems Institute of the RAS, Petra Pervogo St., 4a, 152021, Veskovo, Russian Federation
}

\begin{abstract}
Introduction: Modern ways to develop intelligent problem solvers have shortcomings in the efficiency of their application for planning purposeful behavior of autonomous intelligent mobile systems in a priori undescribed conditions of a problem environment. Purpose: Developing a model of knowledge representation and processing which would provide the ways to organize purposeful activity of autonomous intelligent mobile system in uncertain environment. Methods: Synthesis of frame-like behavior scenarios in the form of polyvariable conditionally dependent predicates whose structure includes complex variables as well as related variables of types "object", "event" and "relationship"; synthesis of heuristic rules for knowledge representation in the process of purposeful behavior planning. In order to represent complex variables in polyvariable conditionally dependent predicates, fuzzy semantic networks are used which can represent knowledge of variously purposed intelligent systems without regard to particular knowledge domains, being adaptable to a priori undescribed operational conditions. Results: We have proposed a structure of various polyvariable conditionally dependent predicates. On their base, an autonomous intelligent mobile system can organize various activities in a priori undescribed and unstable problem environments. Specially developed knowledge processing tools allow such a system to automatically plan its purposeful behavior in a space of subtasks during the fulfilment of tasks formulated for it. Practical relevance: The obtained results can be efficiently used in building intelligent problem solvers for autonomous intelligent mobile systems of various purpose, capable of performing complex tasks in a priori undescribed operational conditions.
\end{abstract}

Keywords - intelligent mobile system, a priori undescribed problem environment, polyvariable conditionally dependent predicates, formulated task, behavior planning.

For citation: Melekhin V. B., Khachumov M. V. Planning polyphase behavior of autonomous intelligent mobile systems in uncertain environments. Informatsionno-upravliaiushchie sistemy [Information and Control Systems], 2021, no. 4, pp. 28-36. doi:10.31799/16848853-2021-4-28-36

\section{Introduction}

The development of autonomous intelligent mobile systems (AIMS) of various purposes, capable of solving complex problems in real a priori undescribed problem environments (PE) is crucial for the modern AI research. It requires a model of knowledge representation and processing which would help an AIMS to plan purposeful activity in uncertain environments, usually on the base of an airborne intelligent problem solver with limited resources. This model should provide the AIMS with the following features:

- Adaptation to the current operational conditions. Various situations possible in a PE are transformable according to certain rules which are usually defined in general terms, without regard to particular knowledge domains, but should be particularized. The objects in the PE should then be transformed into their specified state.

- Purposeful activity should be planned both in the space of subtasks and in the space of states, according to the form in which the specified activity purpose is represented, with the complexity acceptable for the airborne computer. This endows the AIMS with fairly powerful functional abilities, making it capable of solving complex practical problems in all kinds of PE.

As for the first AIMS feature mentioned above, it should be noted that the modern models of knowledge representation and processing cannot provide its effective implementation because of the following main reasons.

1. There are certain limitations due to the use of network intelligence or neural networks in order to build computing units for intelligent problem solvers [1-3] which, after self-training or training, process visual data using various fish-swarm [4-6] or genetic algorithms [7-9]. This approach can efficiently organize only reflexive behaviour of an AIMS by modelling visual-action thinking of living systems [10]. In its turn, it allows the AIMS to solve a number of practical problems in uncertain environments [11], but does not provide ways to effectively plan its behavior when implementing complex tasks which demand time-consuming transformations of various situations in the AIMS by purposeful movement and manipulation of objects inside 
the environment. Hence, in order to solve complex problems, the AIMS, in addition to its visual-action thinking, should be capable of visual-image and conceptual thinking. In other words, it should have inference tools based on the knowledge representation model and information from the PE [10].

2 . In the field of algorithmic intelligence or applying the known models of knowledge representation and processing developed within the logical framework [12-14] and network models [13, 15], the main limitations are as follows. In the first place, an AIMS cannot afford the high inference complexity based on logical models of knowledge representation which requires a high-performance computer, often a bulky one. As for the known network models of knowledge representation (for example, semantic networks), they allow you to build a sufficiently expressive model of a given knowledge domain. However, the lack of effective inference procedures for semantic networks which could be the base for automated planning of AIMS behavior, and close association of these procedures with a particular knowledge domain considerably restrict the ways of using these models in intelligent problem solvers of AIMS which can purposefully function in PE.

In the second place, if, for example, the inference has a linear complexity, as stated by the authors who follow the MIVAR approach [16], its support will require a detailed $\mathrm{PE}$ model in a given knowledge domain. On the one hand, building such a model for a real PE without involving any bulky structures seems to be practically impossible [17]. On the other hand, the need of such a model does not allow us to use the logical approach for organizing purposeful AIMS behavior in uncertain environments. However, as follows from the above, the ability of an AIMS to perform complex tasks in uncertain PE is exactly what we want.

In order to endow an AIMS with the second feature mentioned above, associated with building a model of knowledge representation and processing without regard to particular knowledge domains, organizing inference in uncertain environments with a complexity affordable for an airborne computer, we can use frame-like scenarios of solving typical behavior subproblems [18] based on fuzzy semantic networks [19]. These scenarios allow the AIMS to build complex programs of purposeful activity in the space of state, with polynomial complexity of inference.

However, this approach is not optimal for problems associated with the need to plan polyphase behavior when at each stage of its implementation you have new operational conditions in the PE. Generally, polyphase behavior should be considered as AIMS activity which consists of several stages. At each stage, the intelligent system must automatically build and implement an activity plan en- suring the achievement of its respective behavioral subgoal. After that, in most cases, the operational conditions of the AIMS fully change, and the system focuses on achieving the subgoal of the next stage. The achievement of the subgoals of all polyphase behavior stages means that the AIMS has accomplished its task.

In other words, the knowledge representation model proposed in [18] does not ensure that an AIMS can fulfil complex tasks whose implementation requires purposeful movement and manipulation of objects in various conditions of an a priori undescribed environment. In this connection, the necessity arises to develop standardized structures of a knowledge representation model which would help an AIMS to plan polyphase behavior in dynamically changing operational conditions.

In this work, we propose an approach which allows you to organize polyphase behavior of an AIMS in a priori undescribed PE conditions. Our approach assumes creating a model of knowledge representation and processing based on standardized structures which are polyvariable conditionally dependent predicates (PCDP). Generally, a PCDP structure, in contrast to conventional predicates [13], can include:

- complex variables described using active fuzzy semantic networks (AFSN) [19], which allow you to define various situations and subsituations of the environment specifying them in general terms, without regard to particular knowledge domains;

- miscellaneous variables (in fact, connected), such as "objects" of the problem environment, "events" happening in the PE, and "relationships" observed between the objects, events and AIMS, being descriptive for their influence on the current state on the intelligent system and its behavior.

\section{Statement of the problem}

Let us consider an AIMS equipped with a manipulator, a transportation cart, and technical vision, capable of performing a set of various complex operations $B_{1}=\left\{b_{j_{1}}\right\}, j_{1}=\overline{1, m_{1}}$. For example, it can move specified objects in the PE, find objects in a certain PE zone, transform the current environment situation when it is necessary for achieving one of its behavioral subgoals, etc. Each complex operation $b \in B$ of this kind is implemented by the AIMS which performs a certain sequence of elementary operations $B_{2}=\left\{b_{j_{2}}\right\}, j_{2}=\overline{1, m_{2}}$. These can be operations such as "coming up to an object", "seizing the object", etc. Thus, AIMS is a system capable of moving and manipulating PE objects $O=\left\{o_{j_{3}}\left(X_{j_{3}}, o_{j_{3}}^{*}\right)\right\}, j_{3}=\overline{1, m_{3}}$, where is a set of 
markers providing the ways for the AIMS to identify objects of the PE and perform certain elementary manipulations with them; is the current state $j_{3}$ of an object in the environment.

In general, an unstable $\mathrm{PE}$ can be characterized by its set of objects $o_{j_{3}}\left(X_{j_{3}}, o_{j_{3}}^{*}\right) \in O$ and events $Y=\left\{y_{j_{4}}\left(Y_{j_{4}}\right)\right\}, j_{4}=\overline{1, m_{4}}$ which happen independently of the AIMS. The occurrence of such events leads to various changes in the PE which can prevent the AIMS from successfully performing certain elementary operations $b \in B$ where is a set of markers which determine the event Such an event can be, for example, the appearance of an object in the PE that blocks a passage.

Knowledge representation model, in accordance to the functional purpose of the AIMS, consists of a set of PCDP. Using their different combinations, an intelligent system can design a behavioral plan in order to solve various subproblems of its task. In each particular case, these PCDP serve for specifying an ordered sequence of elementary operations $b \in B$ whose completion ensures that their respective complex operations $b \in B$ are performed. During the inference, the values of different variables in a PCDP are determined more precisely, based on the target task formulated by the AIMS and visual data reflecting the current state of the PE.

The target task is formulated by the AIMS in a procedural representation form as a sequence of complex operations $b \in B$ which have to be performed for its implementation. For example, locate the object $o_{i_{2}}\left(X_{i_{2}}, o_{i_{2}}^{*}\right) \in O$ in a preset square of the $\mathrm{PE}$; transfer this object into the desired state $o_{j}^{* *}$ taking into account the fact that the PE can produce certain events $y_{i_{3}}\left(Y_{i_{3}}\right) \in Y$ keeping the AIMS from performing the respective elementary operations.

We have to develop:

- structure and content of variably purposed PCDP allowing the AIMS to automatically plan its purposeful behavior in order to fulfil the formulated tasks;

- knowledge processing procedures as a part of automated planning of AIMS behavior on the base of PCDP in order to build and solve ordered sequences of behavioral subproblems.

\section{Content and functional purpose of PCDP}

Generally, an AIMS knowledge representation model is a specified set of standardized frame-like structures built on the base of the following PCDP types.

1. Dyadic polyvariable conditionally dependent predicates of the 1st type

$$
\text { “ }: P_{i_{1}}\left(S_{1}^{*}\left(i_{1}\right), x_{i_{1}}^{*}\left(X_{i_{1}}^{*}\right), o_{j_{3}}^{* * *}\right), i_{1}=\overline{1, n_{1}}, n_{1} \leq m_{3} \text { " }
$$

determining the following chains of elementary operations:

$$
\begin{gathered}
L_{i_{1}}:\left\langle<o_{j_{3}}^{* 1} \& b_{j_{2}}^{1},\right. \\
\left.b_{j_{2}}^{2} \rightarrow \ldots \rightarrow o_{j_{3}}^{* k} \& b_{j_{1}}^{k} \rightarrow \ldots o_{j_{3}}^{* h} \& b_{j_{1}}^{h} \rightarrow o_{j_{3}}^{* *}\right\rangle, \\
k=\overline{1, h_{j_{3}}},
\end{gathered}
$$

which ensure that the AIMS performs complex operations $b \in B$ as their identifiers.

These chains of operations manipulate certain PE objects $o_{j_{3}}\left(X_{j_{3}}, o_{j_{3}}^{* k}\right) \in O$ in order to transfer them from a random $(k)$ current state into a target state $o_{j}^{* *}$ when, for various problem environment objects, the condition $X_{i_{1}}^{*} \subseteq X_{j_{3}}$ is true, where

is the total number of permissible states of the object;

is a dyadic predicate symbol with the following meaning: "Transfer the object $x_{i_{1}}^{*}\left(X_{i_{1}}^{*}\right)$ from $\mathrm{a}$ random current state into a target state $o_{j}^{* *}$ by launching the respective subchain of operations $L_{i_{1}}^{*}: o_{j_{3}}^{* k} \& b_{j_{2}}^{k} \rightarrow \ldots \rightarrow o_{j_{3}}^{* d} \& b_{j_{2}}^{d} \rightarrow o_{j_{3}}^{* *}, L_{i_{1}}^{*} \subseteq L_{i_{1}}$, which brings result if the PE satisfies the conditions determined by the complex variable $S_{1}^{*}\left(i_{1}\right)$;

$o_{j_{3}}^{*_{k}} \& b_{j_{2}}^{k} \rightarrow o_{j_{3}}^{* k+1}$ is an elementary behavioral act, meaning that if the object $o_{j_{3}}\left(X_{j_{3}}, o_{j_{3}}^{* k}\right)$ is in the state then the AIMS needs to launch the op-

eration to transfer it into the state

$S_{1}\left(i_{1}\right)$ is a complex variable represented in the form of AFSN $G_{i_{1}}=\left(V_{i_{1}}, E_{i_{1}}\right)$. The nodes of the network are marked with the following sorts of variables: “objects" $x_{i_{2}}^{*}\left(X_{i_{2}}^{*}\right), i_{2}=\overline{1, m_{5}}, \quad m_{5}<m_{3}$ and "events" $d_{i_{3}}^{*}\left(X_{i_{3}}^{*}\right), i_{3}=\overline{1, m_{6}}, m_{6}<m_{4}$. These variables are given their values in the current conditions by way of their respective substitution by objects $o_{j_{3}}\left(X_{j_{3}}, o_{j_{3}}^{* k}\right) \in O$ and events $d_{j_{4}}\left(X_{j_{4}}\right) \in D$ which the AIMS perceives from the PE when the conditions $X_{i_{1}}^{*} \subseteq X_{j_{3}}$ and $X_{i_{3}}^{*} \subseteq X_{j_{4}}$ are true for them. The ribs of the AFSN are determined by the following kinds of "relationship" variables:

- If a rib in the network is incident to the nodes marked with object variables, or one of them is marked with an object variable and the second one is marked with the AIMS, then it is determined by a summarized state space relationship. It can be, for example, the distance between the AIMS and the object.

- In the case when a rib of the network is incident to a node marked with a PE object and to another one marked with a PE event, it should be marked with a relationship which generally determines how this event affects the state of its adjacent object. 
- If a rib in the network is incident to a node marked with the AIMS and to a node marked with a PE event, then it is determined by a summarized relationship which shows how this event affects a certain aspect of the intelligent system activity: for example, interfering with the movement.

It should be noted that a generalized representation of various relationships in AFSN is determined using the intervals of numerical values of their respective linguistic variable terms found by expertise [20].

It should also be noted that when the object variables $x_{i_{1}}^{*}\left(X_{i_{1}}^{*}, x_{i_{1}}^{* * *}\right)$ in predicates $P_{i_{1}}\left(S_{1}^{*}\left(i_{1}\right), x_{i_{1}}^{*}\left(X_{i_{1}}^{*}\right), o_{j_{3}}^{* *}\right)$ receive values of random PE objects $o_{j_{3}}\left(X_{j_{3}}, o_{j_{3}}^{*}\right) \in O$ and slots of complex variables $S_{1}^{*}\left(i_{1}\right)$ receive values of appropriate objects, events, and relationships between them in the $\mathrm{PE}$, we get statements in the format $P_{j_{1}}\left(S_{1}\left(i_{1}\right), o_{j_{3}}\left(X_{j_{3}}, o_{j_{3}}^{* k}\right)\right)$. These statements are true if and only if for the current PE situation the following conditions are satisfied: $X_{i_{1}}^{*} \subseteq X_{j_{3}}, \quad o_{j}^{* k} \neq o_{j}^{* *}$ and $S_{1}\left(i_{1}\right) \approx S_{1}^{*}\left(i_{1}\right)$, where $S_{1}\left(i_{1}\right) \approx S_{1}^{*}\left(i_{1}\right)$ means a fuzzy equality [19] between the passive fuzzy semantic network $S_{1}\left(i_{1}\right)$ determining the current PE subsituation, and the network $S_{1}^{*}\left(i_{1}\right)$ which corresponds to a complex variable of the desired PCDP. The truth of these conditions in the current PE situation is a prerequisite for the AIMS to successfully perform the respective subchains of elementary operations $o_{j_{3}}^{* k} \& b \rightarrow \ldots o_{j_{3}}^{* d} \& b_{j}^{d} \rightarrow x_{i}^{* * *}$. The formal description of the current PE subsituation $S_{1}\left(i_{1}\right)$ used by the AIMS during the inference is formed on the base of visual data in the intelligent problem solver via modification of the $\operatorname{AFSN} S_{1}\left(i_{1}\right)$ by substitution of particular objects, events and relationships between them in the PE.

2. Dyadic PCDP of the 2nd type

$$
\text { “ } b_{j_{1}}^{2}: P_{i_{2}}\left(S_{1}^{*}\left(j_{1}, i_{2}\right), S_{2}^{*}\left(j_{1}, i_{2}\right)\right), i_{2}=\overline{1, n_{2}},,
$$

where is a predicate symbol with the following meaning: “ : in order to transform the current PE subsituation corresponded by a complex variable $S_{1}^{*}\left(j_{1}, i_{2}\right)$ into a subsituation determined by a complex variable $S_{2}^{*}\left(j_{1}, i_{2}\right)$ a tuple of elementary operations $\left\langle b_{j_{2}}^{1}, b_{j_{2}}^{2}, \ldots, b_{j_{2}}^{d}\right\rangle$ should be performed".

3. Dyadic and polyadic PCDP of the 3rd type

$$
\begin{gathered}
\text { " } b_{j_{1}}^{3,1}: P_{i_{3}}\left(S_{3,1}^{*}\left(i_{3}\right), y_{i_{3}}^{*}\left(Y_{i_{3}}^{*}\right)\right), i_{3}=\overline{1, m_{3}} " \\
\text { and “ } b_{j_{1}}^{3,2}: P_{i_{3}}\left(S_{3,2}^{*}\left(i_{3}\right), y_{1, i_{3}}^{*}\left(Y_{1, i_{2}}^{*}\right), \ldots, y_{k, i_{3}}^{*}\left(Y_{k, i_{3}}^{*}\right)\right. \text { ", }
\end{gathered}
$$

determining tuples of elementary operations $\left\langle b_{j_{2}}^{1}, b_{j_{2}}^{2}, \ldots, b_{j_{2}}^{d}\right\rangle$ which are necessary for the complex operation neutralizing the influence of separate $y_{i_{3}}\left(Y_{i_{3}}\right) \in Y$ and mutually related $\mathrm{PE}$ events $\left\langle y_{i_{3}}^{1}\left(Y_{i_{3}}^{1}\right), \ldots, y_{i_{3}}^{k}\left(Y_{i_{3}}^{k}\right) \in Y\right\rangle, \quad$ respectively, which negatively affect the purposeful activity of the AIMS. In the last expression, $y_{i_{3}}^{*}\left(Y_{i_{3}}^{*}\right)$ are event variables which receive values of random events $y_{i_{3}}\left(Y_{i_{3}}\right) \in Y$ observed by the AIMS in the PE when $Y_{i_{3}}^{*} \subseteq Y_{j_{4}}$ is true.

$S_{3,1}^{*}\left(i_{3}\right)$ is a complex variable needed for checking certain $\mathrm{PE}$ conditions which provide that the AIMS successfully performs the operation tuple $\left\langle b_{j_{2}}^{1}, b_{j_{2}}^{2}, \ldots, b_{j_{2}}^{d}\right\rangle$ neutralizing the influence of an event observed in the environment to its further purposeful behavior.

Observing PE events $y_{i_{3}}\left(Y_{i_{3}}\right) \in Y$ determined by the variables $y_{i_{5}}^{*}\left(Y_{i_{5}}^{*}\right) \in Y^{*}$ stimulates AIMS unconditional reactions $b_{j_{2}}^{1}, b_{j_{2}}^{2}, \ldots, b_{j_{2}}^{d}$ in the case when the AIMS is about to perform operations that can be disturbed by these reactions. Hence, the standard elements in the knowledge representation model of the AIMS should be represented in the form of various combinations of the following PCDP pairs:

$$
\begin{gathered}
\left\langle b_{j_{1}}^{3,1}: P_{i_{3}}\left(S_{3,1}^{*}\left(i_{3}\right), y_{i_{3}}^{*}\left(Y_{i_{3}}^{*}\right)\right),\right. \\
\left.b_{j_{1}}^{1}: P_{i_{1}}\left(S_{1}^{*}\left(i_{1}\right), x_{i_{1}}^{*}\left(X_{i_{1}}^{*}\right), o_{j_{3}}^{* *}\right)\right\rangle ; \\
\left\langle b_{j_{1}}^{3,1}: P_{i_{3}}\left(S_{3,1}^{*}\left(i_{3}\right), y_{i_{3}}^{*}\left(Y_{i_{3}}^{*}\right)\right),\right. \\
\left.b_{j_{1}}^{2}: P_{i_{2}}\left(S_{1}^{*}\left(i_{2}\right), S_{2}^{*}\left(i_{2}\right)\right)\right\rangle .
\end{gathered}
$$

Such pairs allow you to recognize, by their first projection, whether the PE contains events that disturb the operations determined by the predicates which form their second projection. Note that similar pairs can also be formed on the base of $\mathrm{k}$-adic predicates $b_{j_{1}}^{3,2}: P_{i_{3}}\left(S_{3,2}^{*}\left(i_{3}\right), y_{1, i_{3}}^{*}\left(Y_{1, i_{2}}^{*}\right), \ldots, y_{k, i_{3}}^{*}\left(Y_{k, i_{3}}^{*}\right)\right)$. This makes the AIMS capable of automatically recognize, by the characteristics of variables $y_{i_{3}}^{*}\left(Y_{i_{3}}^{*}\right)$, and eliminate in the $\mathrm{PE}$ various mutually related "braking" events $y_{i_{3}}\left(Y_{i_{3}}\right) \in Y$ which disturb the successful performance of the operations determined by the PCDP of the 1st and 2nd types included in these pairs.

4. Dyadic PCDP of the 4th type

$$
b_{j_{1}}^{4, z}: P_{i_{4}}\left(S_{i_{4}}^{* z}, \operatorname{RA}\left(i_{4}\right)\right), z=\overline{1,3} .
$$

The AIMS uses them to determine a purposeful movement routing algorithm $\mathrm{RA}(i)$ according to the specified behavior conditions have one of the following meanings: which can

- the AIMS directly observes a PE object, access to which provides that the current subtask is 
fulfilled. In other words, the system needs to make sure it takes such a position in the PE that the specified object is within its manipulator's working zone. In this case, a PCDP of the 4 th type determines the conditions whose satisfaction launches the local optimal planning algorithms PA(1) which can lay a route of movement to the object in an environment with impediments [21];

- the AIMS needs to meet a target which is a moveable object $o_{i_{2}}\left(X_{i_{2}}, o_{i_{2}}^{*}\right) \in O$ observed in the $\mathrm{PE}$. In this case, on the base of a PCDP of the 4 th type, the AIMS chooses a behavior planning algorithm PA(2) which can figure out the polar coordinates of the meeting point according to the object speed and current movement direction, as well as the probable speed of the AIMS itself. Then, based on the obtained data, the route is laid for the AIMS, ensuring it will meet the object [21];

- the AIMS needs to avoid colliding with a moveable object $o_{i_{2}}\left(X_{i_{2}}, o_{i_{2}}^{*}\right) \in O$ observed in the PE. In this situation, on the base of a PCDP of the 4th type, the AIMS chooses a movement planning algorithm PA(3) which can figure out the polar coordinates of the probable meeting point and lay a route to it. The only difference from $\mathrm{PA}(2)$ is a correction making sure that the AIMS will not meet the object.

5. Polyvariable predicates of the 5th type $b_{j_{1}}^{5}: P_{i_{5}}\left(S_{i_{5}}^{*}, \sqrt{\mathrm{RA}}(4)\right)$ which endow the AIMS with a capability to choose a movement planning algorithm PA(4) for a PE with impediments when the coordinates of its current and target position in the given reference system are specified and expressed in the polyvariable

6. PCDP of the 6th type, determining complex operations $b \in B$ whose performance requires performing, in a cycle, their respective tuples $\left\langle b_{j_{2}}^{1}, b_{j_{2}}^{2}, \ldots, b_{j_{2}}^{d}\right\rangle$ of elementary operations. For example, it can be the complex operation : load into the cart all the PE objects which satisfy the conditions of the object variable $x_{j_{1}}^{*}\left(X_{j_{1}}^{*}\right)$, etc., where

is a set of characteristics necessary for certain PE objects $o_{j_{3}}\left(X_{j_{3}}, o_{j_{3}}^{* k}\right) \in O$ which can be seized by the manipulator's hand and lifted.

Generally, all PCDP of the 6th type have the following structure and content: $b_{j_{1}}^{6}: P_{i_{6}}\left(S_{1}^{*}\left(i_{6}\right), x_{j_{1}}^{*}\left(X_{j_{1}}^{*}\right), \operatorname{IF}\left(S_{2}^{*}\left(i_{6}\right) \vee S_{3}^{*}\left(i_{6}\right)\right)\right)$. Here,

is a predicate symbol meaning the necessity to launch, in a cycle, a tuple of elementary operations $\left\langle b_{j_{2}}^{1}, b_{j_{2}}^{2}, \ldots, b_{j_{2}}^{d}\right\rangle$ in order to perform the complex operation with a set of PE objects $o_{j_{3}}\left(X_{j_{3}}, o_{j_{3}}^{* k}\right) \in O$ for which $X_{j_{1}}^{*} \subseteq X_{j_{1}}$ is true.

$S_{1}^{*}\left(i_{6}\right)$ is an AFSN which can determine the conditions that should be satisfied in the current PE sit- uation to ensure the successful performance of the tuple of elementary operations $\left\langle b_{j_{2}}^{1}, b_{j_{2}}^{2}, \ldots, b_{j_{2}}^{d}\right\rangle$.

$\operatorname{IF}\left(S_{2}^{*}\left(i_{6}\right) \vee S_{3}^{*}\left(i_{6}\right)\right)$ is an operator of checking the conditions $\left\langle b_{j_{2}}^{1}, b_{j_{2}}^{2}, \ldots, b_{j_{2}}^{d}\right\rangle$. For example, when $S_{2}^{*}\left(i_{6}\right)$ is true, it means that all the PE objects $o_{j_{3}}\left(X_{j_{3}}, o_{j_{3}}^{* k}\right) \in O$ are loaded into the cart, and when $S_{3}\left(i_{6}\right)$ is true, it means that the total weight of the objects loaded into the cart has reached its bearing capacity;

$\checkmark$ is an operator showing that the cyclic performance of the operation tuple $\left\langle b_{j_{2}}^{1}, b_{j_{2}}^{2}, \ldots, b_{j_{2}}^{d}\right\rangle$ should be stopped if at least one of the conditions it is applied to is true.

7. PCDP of conditionally dependent predicates of the 7th type which determine the behavior planning tools associated with search in the PE and performing a certain tuple of elementary operations on found objects which satisfy the demands of the specified object variable $x_{j_{1}}^{*}\left(X_{j_{1}}^{*}\right)$. Generally, PCDP of this type can have, for example, the following structure and content:

$$
\begin{gathered}
b_{j_{1}}^{6, f}\left(\left\langle b_{j_{1}}^{4,1}, b_{j_{1}}^{1}\right\rangle\right): P_{i_{6}}\left(\left(\downarrow A _ { i _ { 6 } } ( 5 ) \left\langleb_{j_{1}}^{4,1}: P_{i_{4}}\left(S_{i_{4}}^{* 1}, \operatorname{RA}(1)\right),\right.\right.\right. \\
\left.b_{j_{1}}^{1}: P_{i_{1}}\left(S_{1}^{*}\left(i_{1}\right), x_{i_{1}}^{*}\left(X_{i_{1}}^{*}\right), o_{j_{3}}^{* * *}\right)\right\rangle \\
\text { IF(search is over }) \uparrow \text { 个end }), f=\overline{1, m_{5}},
\end{gathered}
$$

where following the arrow means that if the condition $I F$ is false, you should continue searching for required objects in the specified PE zone.

$A_{i}$ ( ) is an algorithm of search for required $\mathrm{PE}$ objects. It splits the specified zone into segments, taking into account the resolving power of the AIMS machine vision, and scans each segment, looking for the objects. After an object is found in the current segment, the AIMS performs the elementary operations specified by the PCDP $P_{i}\left(S_{i}^{*}, R A(1)\right)$ and $A_{i}$ ( ).

$P_{i}\left(S_{i}^{*}, R A(1)\right)$ is a PCDP which launches the route planning algorithm in order to move toward the found object.

$P_{i_{1}}\left(S_{1}^{*}\left(i_{1}\right), x_{i_{1}}^{*}\left(X_{i_{1}}^{*}\right), o_{j_{3}}^{* *}\right)$ is a PCDP according to which the AIMS performs the operations providing that the object transfers from a random $(k)$ current state into the specified state $o_{j}^{* *}$. After that, we can pass to checking the condition determined by the IF operator.

\section{Knowledge processing procedures in automated planning of AIMS behavior in the space of subtasks}

Generally, decision making in the process of automated planning of purposeful AIMS behavior on 
the base of PCDP in the space of subtasks includes the following main stages of knowledge processing in the intelligent problem solver.

1. The received task is split into behavioral subtargets and their respective subtasks. Each subtask includes one complex operation $b \in B$

2 . From the knowledge representation model, we choose those PCDP which correspond to the selected operations $b \in B$ If the structure of the chosen PCDP contains "object" or "event" variables, we have to take into account the characteristics determining those variables of these predicates that are contained in the task formulated by the AIMS.

3. It has to be decided how independently different subtasks can be implemented. With this goal in mind, for each selected complex operation $b \in B$ starting from the last one, we need to determine whether it is nested in the structure of another PCDP selected according to the task. For example, let the operation $\quad b_{j_{1}}^{1}: P_{i_{1}}\left(S_{1}^{*}\left(i_{1}\right), x_{i_{1}}^{*}\left(X_{i_{1}}^{*}\right), o_{j_{3}}^{* *}\right)$ selected at the stage 2 be included in the structure of a PCDP of the 7th type found on the base of a complex operation $b_{j_{1}}^{6, f}\left(<b_{j_{1}}^{4,1}, b_{j_{1}}^{1}>\right)$. In this case, a PCDP of the 1 st type $b_{j_{1}}^{1}: P_{i_{1}}\left(S_{1}^{*}\left(i_{1}\right), x_{i_{1}}^{*}\left(X_{i_{1}}^{*}\right), o_{j_{3}}^{* *}\right)$ found in the knowledge representation model taking into account the characteristics of the object variable specified in the task received by the AIMS, is substituted into the structure of a polyvariable conditionally dependent predicate of the 7th type.

The process of searching for PCDP continues until having specified and corrected all the predicates which correspond to the independently performed complex operations $b \in B$ in the structure of the task.

4. A plan of behavior is synthesized by concatenation of the PCDP which were found at the stage 3, in the order of their respective complex operations $b \in B$ in the task.

5 . When necessary, at various stage of the formed behavior plan implementation, a tuple of PCDP has to be built, which can help to form a sequence of elementary operations providing certain transformations of the situation perceived in the $\mathrm{PE}$ in order to fulfil the current subtask. For example, at some stage, the AIMS can face the necessity to ensure conditions determined by the polyvariable $S_{2}^{*}\left(j_{1}, i_{2}\right)$ represented in AFSN form. In this case, based on visual data, the intelligent problem solver produces a formal description of the current operational conditions in the form of a passive fuzzy semantic network $G_{T}=\left(V_{T}, E_{T}\right)$. Its nodes $V_{T}$ are marked with PE objects $o_{j_{3}}\left(X_{j_{3}}, o_{j_{3}}^{*}\right) \in O$ and PE events $y_{i_{3}}\left(Y_{i_{3}}\right) \in Y$ while its arcs $E_{T}$ are determined by quantitative estimates of the relationships between the objects, events, and AIMS.

Now, if the AFSN corresponding to the subsituation $S_{1}^{*}\left(j_{1}, i_{2}\right)$ is fuzzily equal to and nested in- to a formal description of the current PE situation [19], then in order to provide the environment conditions determined by the subsituation $S_{2}^{*}\left(j_{1}, i_{2}\right)$, the AIMS performs a tuple of elementary operations $\left\langle b_{j_{2}}^{1}, b_{j_{2}}^{2}, \ldots, b_{j_{2}}^{d}\right\rangle$ found on the base of PCDP $b_{j}: P_{i}\left(S_{1}^{*}\left(j_{1}, i_{2}\right), S_{2}^{*}\left(j_{1}, i_{2}\right)\right)$. Otherwise, this tuple will consist of PCDP of the 2 nd type whose elements satisfy the following conditions:

a) for the first PCDP $P_{i}^{1}\left(S_{1}^{* 1}\left(j_{1}, i_{2}\right), S_{2}^{* 1}\left(j_{1}, i_{2}\right)\right)$ in the structure of the tuple, the AFSN corresponding to the subsituation $S_{1}^{*}\left(j_{1}, i_{2}\right)$ should be fuzzily equal to and nested into the passive fuzzy semantic network $G_{T}=\left(V_{T}, E_{T}\right)$;

b) for all pairs of adjacent PCDP, for example, for $P_{i}^{1}\left(S_{1}^{* 1}\left(j_{1}, i_{2}\right), S_{2}^{* 1}\left(j_{1}, i_{2}\right)\right)$ and $P_{i}^{2}\left(S_{1}^{* 2}\left(j_{1}, i_{2}\right)\right.$, $\left.S_{2}^{* 2}\left(j_{1}, i_{2}\right)\right)$, the $S_{2}^{* 1}\left(j_{1}, i_{2}\right) \approx S_{1}^{* 2}\left(j_{1}, i_{2}\right)$ should be true;

c) for the sought predicate $P_{i}\left(S_{1}^{*}\left(j_{1}, i_{2}\right), S_{2}^{*}\left(j_{1}, i_{2}\right)\right)$ at the last position in the formed tuple and its left adjacent predicate $P_{i}^{2}\left(S_{1}^{* 2}\left(j_{1}, i_{2}\right), S_{2}^{* 2}\left(j_{1}, i_{2}\right)\right)$, the condition $S_{2}^{* k}\left(j_{1}, i_{2}\right) \approx S_{1}^{*}\left(j_{1}, i_{2}\right)$ should be true.

In this case, performing, in the preset order, elementary operations specified by the PCDP in the tuple allows us, by means of consecutive purposeful transformation of the current operational conditions, to ensure that the PE conditions $S_{2}^{*}\left(j_{1}, i_{2}\right)$ are true.

As an example, let us consider the process of AIMS behavior planning associated with the fulfilment of the following task: “ $b_{j_{1}}^{6}\left(<b_{j_{1}}^{4,1}, b_{j_{1}}^{1}\right)$ : in a given PE zone, find all objects $o_{j_{3}}\left(X_{j_{3}}, o_{j_{3}}^{k^{*}}\right) \in O$ possessing the subset of characteristics transfer the found objects from a random current state into a specified state $o_{j}^{* *} ; \quad$ after scanning the specified zone, proceed to the location point".

In order to fulfil this task, at the first step of building a behavior plan based on complex operations $b_{j_{1}}^{6}\left(\left\langle b_{j_{1}}^{4,1}, b_{j_{1}}^{1}\right\rangle\right)$, and we should pick up their respective PCDP from the memory and pass them to the intelligent problem solver. When choosing PCDP of the 1 st type $b_{j_{1}}^{1}: P_{i_{1}}\left(S_{1}^{*}\left(i_{1}\right), x_{i_{1}}^{*}\left(X_{i_{1}}^{*}\right), o_{j_{3}}^{* * *}\right)$, we should remember that its object variable must be determined by a set of characteristics specified in the task received by the AIMS.

At the next step of the planning, it is determined that the operation is included in the structure of the complex operation $b_{j_{1}}^{6}\left(\left\langle b_{j_{1}}^{4,1}, b_{j_{1}}^{1}\right\rangle\right)$, i.e. its performance is not independent. After this, the predicate $b_{j_{1}}^{1}: P_{i_{1}}\left(S_{1}^{*}\left(i_{1}\right), x_{i_{1}}^{*}\left(X_{j_{3}}^{3}\right), o_{j_{3}}^{* * *}\right)$ is substituted into the structure of a PCDP of the 7th type.

At the last step of the planning, a PCDP tuple is built, corresponding to independently performed complex operations $b_{j_{1}}^{6}\left(\left\langle b_{j_{1}}^{4,1}, b_{j_{1}}^{1}\right\rangle\right)$ and 
At the next stage of building an intellectual problem solver for the AIMS, we develop, based on the proposed knowledge representation and processing model, information technologies in order to organize automated planning of purposeful polyphase behavior in the PE. You can read about the methodology and peculiarities of developing hybrid or autonomous intelligent information technologies and systems in such works as [22].

To summarize, we can state that the proposed model of AIMS knowledge representation and processing, unlike the known algorithms of search for decisions in a space of subtasks [11-13], allows you to build procedures for automated planning of polyphase behavior during the implementation of PE tasks of various complexity by means of forming an inference tree without any empty alternatives. This is associated with the fact that generally, on the one hand, the search for a subproblem solution at each behavior planning step assumes choosing several effective operations at once; on the other hand, these operations are chosen in a purposeful way during the search. As for complex problem solution search in a space of subtasks on the base of the known inference procedures, generally it is reduced to brute-force search which, in its turn, leads to a higher dimension of the search space [11-13].

It should also be noted that in the framework of the proposed model, the main operation performed in the problem solver is comparison of different fuzzy semantic networks which are marked graphs. The complexity of this comparison has an order of $Q\left[n^{2}\right]$, where $n$ is the number of nodes in the graphs. Hence, the purposeful behavior planning procedures built on their base will have polynomial complexity, which opens the ways to their efficient implementation on airborne computers of various AIMS.

\section{Conclusion}

1. The proposed standard structures in the form of variously purposed PCDP allow you to build a knowledge representation model for an AIMS without regard to particular knowledge domains, in accordance to its functional purpose. Thus, an intelligent mobile system can adapt to a $\mathrm{PE}$ with a priori undescribed conditions.

2. Generalized development of principles for purposeful behavior planning on the base of a specified set of PCDP provides the ways for its application in intelligent problem solvers of variously purposed AIMS, endowing them with the capability of performing tasks various in complexity and content, in uncertain environments.

3. The completeness of a PCDP set that allows an AIMS to perform variously purposed tasks in a PE with a priori undescribed conditions is determined based on its functional purpose or the class of subproblems that the system will have to solve during its purposeful behavior planning. A given PCDP set is an open model of knowledge representation which can be enriched as the system accumulates experience in various problem environments, different in complexity and content.

\section{Financial support}

This study was supported by the Russian Science Foundation, Grant No. 21-71-10056 (https://rscf.ru/ en/project/21-71-10056/).

\section{References}

1. Yushenko A. S., Lebedev K. R., Zabihafar S. H. The adaptive neural network control of quadrotor helicopter. Nauka i obrazovanie. MGTU im. N. E. Baumana, 2017, no. 07, pp. 262-277. Available at: https://www. elibrary.ru/download/elibrary_30585864 44197366.pdf (accessed 15 August 2021) (In Russian).

2. Korovin Ya. S., Khisamutdinov M. V., Ivanov D. Ya. Experimental researches of methods of neural network analysis of oilfield data. Vestnik nauki i obrazovaniya, 2019, no. 1-1, pp. 17- 26 (In Russian).

3. Bai S., Wang C. Information aggregation and fusion in deep neural networks for object interaction exploration for semantic segmentation. Knowledge-Based Systems, 2021, vol. 218. doi:10.1016/j.knosys.2021. 106843
4. Karpov V. E., Karpova I. P., Kulinich A. A. Social'nye soobshchestva robotov [Social communities of robots]. Moscow, LENAND Publ., 2019. 352 p. (In Russian).

5. Uriol R., Moran A. Mobile robot path planning in complex environments using ant colony optimization algorithm. Proc. 3rd International Conference on Control, Automation and Robotics, Nagoya, 2017, pp. 1521. doi:10.1109/ICCAR.2017.7942653

6. Zhu B., Xie L., Han D., Meng X., Teo R. A survey on recent progress in control of swarm systems. Science China Information Sciences, 2017, vol. 60, no. 7, pp. 1-24. doi:10.1007/s11432-016-9088-2

7. Simon D. Evolutionary Optimization Algorithms. Wiley, 2013. 784 p.

8. Mogilev A. A., Kureichik V. M. Modified genetic project planning algorithm implemented with the use of cloud computing. Izvestiya SFedU. Engineering 
sciences, 2020, no. 2(212), pp. 157-159 (In Russian). doi:10.18522/2311-3103-2020-2-157-169

9. Dong H., Xu Y., Li X., Yang Z., Zou C. An improved ant lion optimizer with dynamic random walk and dynamic opposite learning. Knowledge-Based Systems, 2021, vol. 216. doi:10.1016/j.knosys.2021.106752

10. Melekhin V. B., Khachumov M. V. Forms of thinking of autonomous intelligent agents: features and problems of their organization. Marine Intelligent Technologies, 2020, no 4-1(50), pp. 223-229. doi:10.37220/ MIT.2020.50.4.031

11. Folgheraiter M., Keldibek A., Aubakir B., Gini G., Franchi A. M., Bana M. A neuromorphic control architecture for a biped robot. Robotics and Autonomous Systems, 2019, vol. 120. doi:10.1016/j.robot.2019.07.014

12. Broussard M. Artificial Unintelligence: How Computers Misunderstand the World. MIT Press, 2018. $246 \mathrm{p}$.

13. Russell S., Norvig P. Artificial Intelligence: A Modern Approach. 4 ed. Pearson, 2020. 1216 p.

14. Dushkin R. V. Iskusstvennyj intellect [Artificial Intelligence]. Moscow, DMK Press Publ., 2019. 279 p. (In Russian).

15. Ostrouh A. V., Surkova N. E. Sistemy iskusstvennogo intellekta [Artificial intelligence systems]. Saint-Petersburg, Lan' Publ., 2019. 227 p. (In Russian).

16. Varlamov O. O., Aladdin D. V. On the application of mivar networks for intellectual planning of the behavior of robots in the space of conditions. Izvestiya Kabardino-Balkarskogo nauchnogo centra RAN, 2018, no. 6-2 (86), pp. 75-82 (In Russian).
17. Ford M. Architects of Intelligence: The Truth about AI from the People Building it. Packt Publishing, 2018. $554 \mathrm{p}$.

18. Melekhin V. B., Khachumov M. V. Partitioning complex tasks into subtasks in the process of planning goal-seeking behavior of an integral unmanned aerial vehicle in the state space. Marine Intelligent Technologies, 2020, no. 3-1 (50), pp. 237-244. doi:10.37220/ MIT.2020.49.3.032

19. Melekhin V. B., Khachumov M. V. Fuzzy semantic networks as an adaptive model of knowledge representation of autonomous intelligent systems. Iskusstvennyj intellekt $i$ prinyatie reshenij, 2020, no. 3 , pp. 61-72 (In Russian). doi:10.14357/20718594200306

20. Flegontov A. V., Vilkov V. B., Chernyh A. K. Modelirovanie zadach prinyatiya reshenij pri nechetkih iskhodnyh dannyh [Modeling decision-making problems with fuzzy initial data]. Saint-Petersburg, Lan' Publ., 2020. 332 p. (In Russian).

21. Melekhin V. B., Khachumov M. V. Path planning for purposeful flight of an autonomous aircraft at low altitude in uncertain environment. Aviakosmicheskoe priborostroenie, 2018, no. 1, pp. 18-27 (In Russian).

22. Golenkov V. V., Guliakina N. A., Davydenko I. T., Shunkevich D. V., Eremeev A. P. Ontological design of hybrid semantically compatible intelligent systems based on sense representation of knowledge. Ontologiya proektirovaniya, 2019, vol. 9, no. 1 (34), pp. 132151 (In Russian). doi:10.18287/2223-9537-2019-9-1132-151

УДК 62.506.29.519

doi:10.31799/1684-8853-2021-4-28-36

\section{Планирование полифазного поведения автономных мобильных интеллектуальных систем в условиях} неопределенности

В. Б. Мелехина , доктор техн. наук, профессор, orcid.org/ 0000-0002-7614-2860, pashka1602@rambler.ru M. В. Хачумов ${ }^{б, в}$, канд. физ.-мат. наук, старший научный сотрудник, orcid.org/0000-0001-5117-384X аДагестанский государственный технический университет, Имама Шамиля пр., 70, Махачкала, 367015, РФ бФедеральный исследовательский центр «Информатика и управление» РАН, 60-летия Октября пр., 9, Москва, 117313, РФ

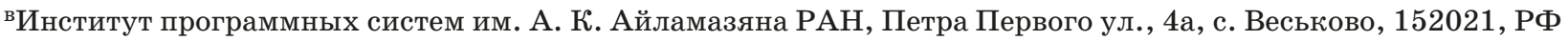

Введение: проведен анализ современных принципов организации интеллектуальных решателей задач, позволивший обозначить их основные недостатки с точки зрения эффективности применения для планирования целенаправленного поведения автономных мобильных интеллектуальных систем в априори неописанных условиях проблемной среды. Цель: разработка модели представления и обработки знаний, позволяющей организовать целенаправленную деятельность автономных мобильных интеллектуальных систем в условиях неопределенности. Методы исследования связаны с синтезом: 1) фреймоподобных сценариев поведения, представляющих собой полипеременные условно-зависимые предикаты, структура которых включает комплексные переменные, а также связанные переменные сорта «объекты», «события», происходящие в среде, и «отношения» между ними; 2) эвристических правил обработки знаний в процессе планирования целенаправленного поведения. Для представления комплексных переменных в полипеременных условно-зависимых предикатах применяются нечеткие семантические сети, позволяющие представлять знания различных по назначению интеллектуальных систем безотносительно к конкретной предметной области и на этой основе адаптироваться к априори неописанным условиям функционирования. Результаты: предложена структура различных по функциональному назначению полипеременных условно-зависимых предикатов, позволяющих автономным мобильным интеллектуальным системам организовать различные виды деятельности в априори неописанных нестабильных проблемных средах. Разработаны инструментальные средства обработки знаний, обеспечивающие автономным мобильным интеллектуальным системам возможность автоматически планировать целенаправленное поведение в пространстве подзадач в процессе выполнения 
сформулированных им заданий. Практическая значимость: использование полученных результатов повышает эффективность построения интеллектуальных решателей задач для автономных мобильных интеллектуальных систем различного назначения, способных выполнять сложные задания в априори неописанных условиях функционирования.

Ключевые слова - интеллектуальная мобильная система, априори неописанная проблемная среда, полипеременные условно-зависимые предикаты, сформулированное задание, планирование поведения.

Для цитирования: Melekhin V. B., Khachumov M. V. Planning polyphase behavior of autonomous intelligent mobile systems in uncertain environments. Инфорлационно-управляющие системы, 2021, № 4, с. 28-36. doi:10.31799/1684-8853-2021-4-28-36

For citation: Melekhin V. B., Khachumov M. V. Planning polyphase behavior of autonomous intelligent mobile systems in uncertain environments. Informatsionno-upravliaiushchie sistemy [Information and Control Systems], 2021, no. 4, pp. 28-36. doi:10.31799/16848853-2021-4-28-36

\section{УВАЖАЕМЫЕ АВТОРЫ!}

Научные базы данных, включая SCOPUS и Web of Science, обрабатывают данные автоматически. С одной стороны, это ускоряет процесс обработки данных, с другой - различия в транслитерации ФИО, неточные данные о месте работы, области научного знания и т. д. приводят к тому, что в базах оказывается несколько авторских страниц для одного и того же человека. В результате для всех по отдельности считаются индексы цитирования, что снижает рейтинг ученого.

Для идентификации авторов в сетях Thomson Reuters проводит регистрацию с присвоением уникального индекса (ID) для каждого из авторов научных публикаций.

Процедура получения ID бесплатна и очень проста, есть возможность провести регистрацию на 12-ти языках, включая русский (чтобы выбрать язык, кликните на зеленое поле вверху справа на стартовой странице): https://orcid.org 